\title{
DNA methyltransferase expression and DNA methylation in human hepatocellular carcinoma and their clinicopathological correlation
}

\author{
BONG-KYEONG OH ${ }^{1 *}$, HAERYOUNG KIM ${ }^{2 *}$, HYE-JUNG PARK ${ }^{3}$, YHONG-HEE SHIM ${ }^{3}$, \\ JINSUB CHOI ${ }^{4}, \mathrm{CHANIL} \mathrm{PARK}^{5}$ and YOUNG NYUN PARK ${ }^{5}$
}

\begin{abstract}
${ }^{1}$ Cancer Metastasis Research Center, Yonsei University College of Medicine, 134 Shinchon-dong, Seodaemoon-gu, Seoul 120-752; ${ }^{2}$ Department of Pathology, Seoul National University Bundang Hospital, 300 Gumi-dong, Bundang-gu, Seongnam, Kyeonggi-do 463-707; ${ }^{3}$ Department of Bioscience and Biotechnology, and Bio/Molecular Informatics Center and Institute of Biomedical Science and Technology, Konkuk University,

1 Hwayang-dong, Gwangjin-gu, Seoul 143-701; ${ }^{4}$ Department of General Surgery, Yonsei University College of Medicine;

${ }^{5}$ Department of Pathology and Institute of Gastroenterology, Center for Chronic Metabolic Disease, Innovation Cluster

for Bio-Fusion Industry based on Nanotechnology (ICBIN), Brain Korea 21 Project for Medical Science,

Yonsei University College of Medicine, 134 Shinchon-dong, Seodaemoon-gu, Seoul 120-752, Korea
\end{abstract}

Received January 30, 2007; Accepted March 8, 2007

\begin{abstract}
Aberrant DNA methylation on $\mathrm{CpG}$ islands is one of the most consistent epigenetic changes in human cancers, and the methylation process is catalyzed by DNA methyltransferase (DNMT). We evaluated i) the mRNA levels of three DNMTs; DNMT1, DNMT3a and DNMT3b, in 25 hepatocellular carcinomas (HCCs), in their corresponding noncancerous liver tissues and in 7 normal livers by using realtime reverse transcriptase-polymerase chain reaction; ii) nuclear expression of DNMT1 and DNMT3a proteins in the HCCs by immunohistochemistry, iii) the methylation status of 5 genes; p16, p15, E-cadherin, HIC-1 and RASSF1A in the same tissues, and iv) the relationships between the above results and the clinicopathological characteristics, including prognosis. The differences in mRNA expression levels for
\end{abstract}

Correspondence to: Dr Young Nyun Park, Department of Pathology and Brain Korea 21 Project for Medical Science, Yonsei University College of Medicine, 134 Shinchon-dong, Seodaemoon-gu, Seoul 120-752, Korea

E-mail: young0608@yumc.yonsei.ac.kr

${ }^{*}$ Contributed equally

Abbreviations: DNMT, DNA methyltransferase; HCC, hepatocellular carcinoma; MSP, methylation-specific polymerase chain reaction; RT-PCR, reverse transcriptase-polymerase chain reaction

Key words: DNA methylation, DNA methyltransferase, hepatocellular carcinoma
DNMT1, DNMT3a and DNMT3b were statistically significant between HCC and normal livers $(p<0.001), \mathrm{HCC}$ and chronic hepatitis $(\mathrm{p}<0.001)$ and HCC and cirrhosis $(\mathrm{p}<0.001)$. An increase in mRNA expression levels of $>4$-fold for DNMT3b in HCCs was significantly associated with a poorer overall survival $(p=0.027)$ and shorter metastasis-free survival $(\mathrm{p}=0.0299)$. A poorer recurrence-free survival was noted in HCCs with a $>4$-fold increase in DNMT3a mRNA ( $\mathrm{p}=0.0120)$. The average numbers of methylated genes were $0,1.27,1.38$ and 2.72 for normal livers, chronic hepatitis, cirrhosis and $\mathrm{HCCs}$, respectively, and this progressive increase from normal livers to chronic hepatitis/cirrhosis through HCC may suggest that tumor suppressor gene methylation is an early event in hepatocarcinogenesis. These results first suggest that hepatocarcinogenesis involves an increased expression of DNMT1, DNMT3a and DNMT3b mRNA and a progressive increase in the number of methylated genes from normal liver, chronic hepatitis/cirrhosis to HCC and secondly that an increase in the DNMT3a and DNMT3b mRNA levels in HCCs relative to their non-cancerous tissues may be a predictor of poor survival.

\section{Introduction}

Gene silencing by aberrant methylation of promoter $\mathrm{CpG}$ islands is an epigenetic alteration frequently found in many types of human cancers. The methylation of $\mathrm{CpG}$ islands, 0.5 to $2-\mathrm{kb}$ regions rich in cytosine-guanine dinucleotides at the promoter region of approximately half of all human genes, is maintained strictly through DNA replication and mitosis by the action of DNA methyltransferase (DNMT) in normal cells; however, hypermethylation in specific $\mathrm{CpG}$ island sequences has been frequently seen in malignancies (1-3). The role of hypermethylation on $\mathrm{CpG}$ islands has recently been implicated in hepatocarcinogenesis, and the list of 
tumor suppressor genes affected by such epigenetic silencing in hepatocellular carcinomas (HCCs) is expanding (4-9). Moreover, the number of methylating events in HCCs has been demonstrated to be higher than in cirrhotic livers, providing evidence that a stepwise progression of methylating events may be a feature of hepatocarcinogenesis $(4,5,7)$.

Tumor suppressor genes affected by this epigenetic alteration include those associated with cell cycle progression and those related to cell-to-cell adhesion. p15INK4b and pl6INK4a encode two cyclin-dependent kinase 4/6 inhibitor proteins and have been shown to be affected by $\mathrm{CpG}$ island hypermethylation in HCCs $(5-7,9,10)$. Inactivation of these two genes results in $\mathrm{Rb}$ phosphorylation, entry to the $\mathrm{S}$ phase of the cell cycle and subsequent cell proliferation. RASSF1A, a major isoform of RASSF1 located at $3 \mathrm{p} 21.3$, is another cell cycle-related tumor suppressor protein which inhibits cyclin D1 and hence induces G1 phase arrest. Methylation of the RASSF 1A promoter has been demonstrated at high frequency in many solid tumors, including HCCs, and also in cirrhotic livers and chronic hepatitis $(5,10,11)$. Of the intercellular adhesion-related genes, E-cadherin is a tumor suppressor gene located in 16q22.1 encoding a $\mathrm{Ca}^{2+}$-dependent cell adhesion molecule. Methylation of its promoter region has been associated with reduced expression of the protein, resulting in loss of intercellular adhesiveness and tissue destruction in HCCs (12). In addition, E-cadherin methylation in HCCs has been shown to be associated with a poor prognosis (5). Another tumor suppressor gene called hypermethylated-in-cancer 1 (HIC-1) has been associated with $\mathrm{CpG}$ island hypermethylation in HCCs, and at a lower frequency in cirrhosis and chronic hepatitis (13).

The mammalian DNMT is encoded by three distinct families of DNMT genes; DNMT1, DNMT2 and DNMT3. DNMT1 is the most abundant DNMT involved in the maintenance of methylation (14), and DNMT3 functions as de novo methyltransferase and consists of two related genes, DNMT3 $a$ and DNMT3b (15). The function of DNMT2 remains to be revealed (16). DNMTs catalyze the methylation of $\mathrm{CpG}$ islands and are possibly responsible for DNA hypermethylation of tumor suppressor gene promoters in tumorigenesis, as increased expression levels have been demonstrated in human malignancies $(1,17)$. With regards to hepatocarcinogenesis, the expression levels of DNMT1 mRNA and protein have been shown to be significantly higher in HCCs compared to non-cancerous liver tissues, DNMT3a mRNA expression either similar or higher in HCCs than in non-neoplastic liver tissues, and expression levels of DNMT3b mRNA consistently higher in HCCs $(6,10,18,19)$. A recent clinicopathological analysis by Saito et al described a significant correlation between DNMT1 protein expression and lower recurrence-free and overall survival rates in HCC patients (20). The correlation between the clinicopathological findings of HCCs and the mRNA levels of DNMT1, DNMT3a and DNMT3b, however, remain to be determined. Furthermore, a clear relationship between DNMT mRNA or protein expression and aberrant methylation of tumor suppressor gene promoters has not yet been established $(6,18,21,22)$.

In this study, we examined the mRNA expression levels of DNMT1, DNMT3a and DNMT3b by real-time quantitative polymerase chain reaction (RT-PCR) in HCC, paired nonneoplastic liver tissue and normal liver tissue, and the immunohistochemical expression of DNMT1 and DNMT3a proteins in HCC. We also determined the methylation status of $\mathrm{CpG}$ islands of 5 genes; p16, p15, E-cadherin, HIC-1 and RASSF 1A, in the same tissues. The results were correlated with the clinicopathological characteristics of the examined cases, including recurrence and metastasis-free survival and overall survival.

\section{Materials and methods}

Patients and samples. Tissue specimens from 25 primary HCCs and their corresponding non-cancerous liver tissue were provided by the Liver Cancer Specimen Bank from the National Research Resource Bank Program of the Korea Science and Engineering Foundation in the Ministry of Science and Technology from 2000 to 2001. The clinicopathological features of the 25 cases are shown in Table I. The patient population comprised 16 men and 9 women, with a mean age of 54 years (range, 35-67 years; SD, 9 years). Twenty-two cases were confirmed as being hepatitis B virus-associated by serological studies for hepatitis B virus antigens, 1 case was associated with alcohol abuse and the remaining 2 cases revealed no specific etiology. The histological grades by Edmondson-Steiner for the HCCs were grade 2 for 16 cases and grade 3 for the remaining 9 cases. Vascular invasion was noted in 14 cases, and satellite nodule formation in 6 cases. Histological examination of the non-cancerous liver tissue revealed chronic hepatitis in 11 cases, cirrhosis in 13 cases and histologically normal in 1 case. For comparison, normal liver tissues were also obtained from 7 patients who had undergone surgical resection for metastatic carcinomas, hemangioma or focal nodular hyperplasias.

Real-time RT-PCR. Tissues weighing 20-30 mg were powdered by grinding with a pestle in liquid nitrogen, transferred to a microcentrifuge tube, and homogenized using a QIAshredder (Qiagen, GmbH, Germany). Total RNA was isolated using a Qiagen column, according to the manufacturer's instructions. The total RNA was pretreated with RNase-free DNase I (Takara, Shiga, Japan) for $30 \mathrm{~min}$ at room temperature to remove the genomic DNA prior to cDNA synthesis. The cDNA synthesis was performed at $42^{\circ} \mathrm{C}$ for $50 \mathrm{~min}$ in $20 \mu \mathrm{l}$ containing $1 \mu \mathrm{g}$ of the total RNA, 160 pmol of random hexamers (Takara), 200 units of superscript RNase $\mathrm{H}^{-}$reverse transcriptase (Gibco BRL, MD, USA), 20 units of Superasein ${ }^{\mathrm{TM}}$ (Ambion, TX, USA), $0.5 \mathrm{mM}$ dNTP, $10 \mathrm{mM}$ DTT and 1X of the first-strand buffer (Gibco $\mathrm{BRL}$ ), which was further incubated for $15 \mathrm{~min}$ at $70^{\circ} \mathrm{C}$ to denature the enzyme.

Real-time quantitative RT-PCR for DNMT1, DNMT3a and DNMT3b was performed with Assays-on-Demand ${ }^{\mathrm{TM}}$ gene expression products (Applied Biosystems, CA, USA) using the ABI PRISM 7700 sequence detection system (Perkin-Elmer, CA, USA). A standard curve was prepared from 5-fold serial dilutions of the cDNA obtained from the HEK293T cell line, in which the DNMT1, DNMT3a and DNMT3b were highly expressed. The serial dilutions of the cDNA ranged from 0.16-100 ng for DNMT1, DNMT3a and 


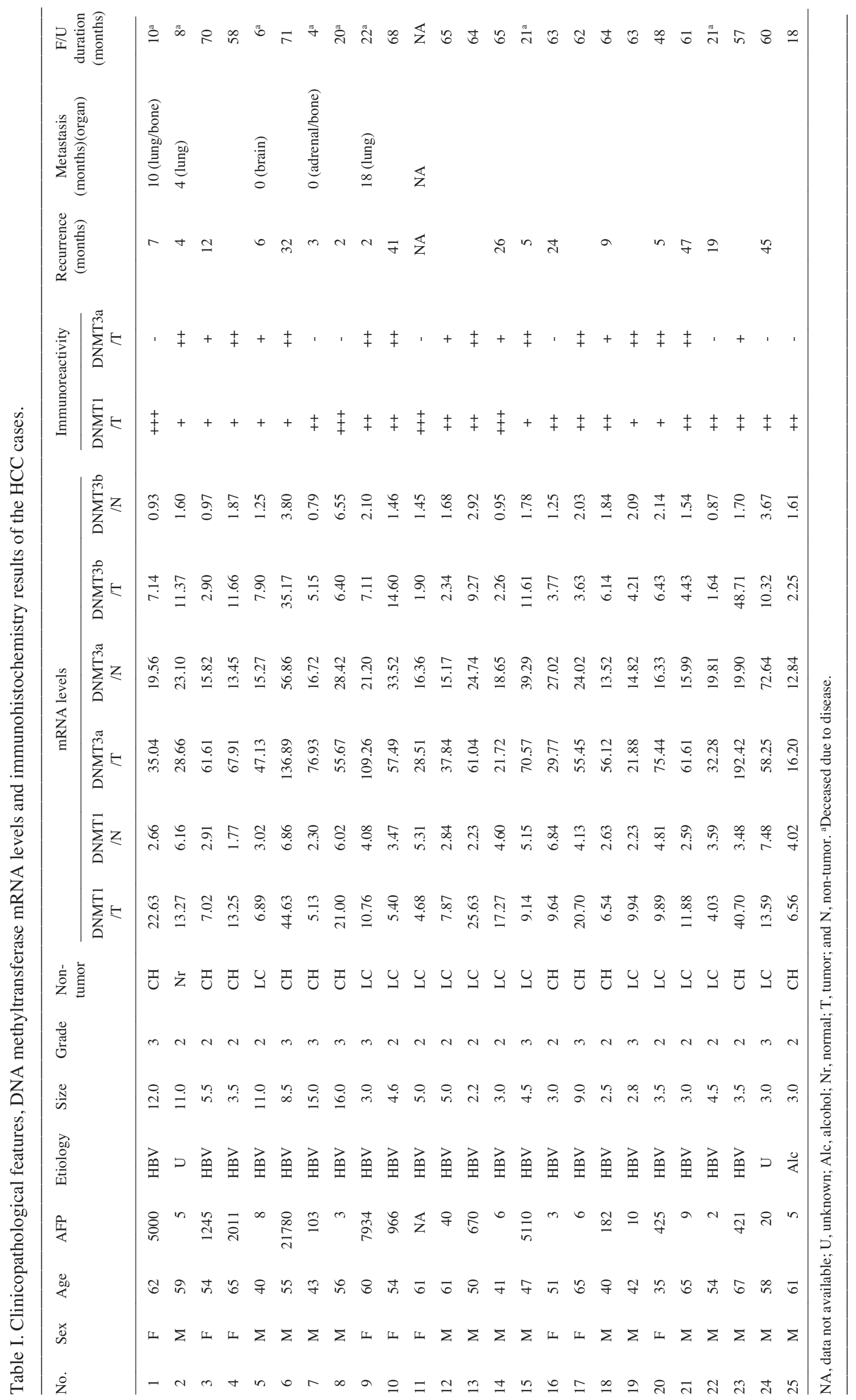


Table II. Primer sequences and conditions for methylation-specific PCR.

\begin{tabular}{|c|c|c|c|c|}
\hline Target genes & & Primer sequences & Size (bp) & Annealing temperature $\left({ }^{\circ} \mathrm{C}\right)$ \\
\hline p16U & $\begin{array}{l}\text { Sense } \\
\text { Antisense }\end{array}$ & $\begin{array}{l}\text { 5'TTATTAgAgggTggggTggATTg3' } \\
\text { 5'CAACCCCAAACCACAACCATAA3' }\end{array}$ & 151 & 65 \\
\hline $\mathrm{p} 16 \mathrm{M}$ & $\begin{array}{l}\text { Sense } \\
\text { Antisense }\end{array}$ & $\begin{array}{l}\text { 5'TTATTAgAgggTggggCggATCgC3' } \\
\text { 5'gACCCgAACCgCgACCgTA3' }\end{array}$ & 150 & 65 \\
\hline $\mathrm{p} 15 \mathrm{U}$ & $\begin{array}{l}\text { Sense } \\
\text { Antisense }\end{array}$ & $\begin{array}{l}\text { 5'TgTgATgTgTTTgTATTTTgTgTT3' } \\
\text { 5'CCATACAATAACCAAACAACCAA3' }\end{array}$ & 154 & 60 \\
\hline $\mathrm{p} 15 \mathrm{M}$ & $\begin{array}{l}\text { Sense } \\
\text { Antisense }\end{array}$ & $\begin{array}{l}\text { 5'gCgTTCgTATTTgCgTT3' } \\
\text { 5'CgTACAATAACCgAACgACCgA3' }\end{array}$ & 148 & 60 \\
\hline E-cadU & $\begin{array}{l}\text { Sense } \\
\text { Antisense }\end{array}$ & $\begin{array}{l}\text { 5'gTgggCgggTCgTTAgTTTC3' } \\
\text { 5'CTCACAAATACTTTACAATTCCACg3' }\end{array}$ & 174 & 57 \\
\hline E-cadM & $\begin{array}{l}\text { Sense } \\
\text { Antisense }\end{array}$ & $\begin{array}{l}\text { 5'ggTggTgggTTgTTAgTTTTgT3' } \\
\text { 5'AACTCACAAATCTTTACAATTCCAACA3' }\end{array}$ & 172 & 57 \\
\hline RASSF1AU & $\begin{array}{l}\text { Sense } \\
\text { Antisense }\end{array}$ & $\begin{array}{l}\text { 5'TTTgTTggAgTgTgTTAATgT3' } \\
\text { 5'CAAACCCCACAAACTAAAAACAA3' }\end{array}$ & 108 & 60 \\
\hline RASSF1AM & $\begin{array}{l}\text { Sense } \\
\text { Antisense }\end{array}$ & $\begin{array}{l}\text { 5'gggTTTTgCgAgAgCgC3' } \\
\text { 5'gCTAACAAACgCgAACC3' }\end{array}$ & 169 & 64 \\
\hline HIC-1U & $\begin{array}{l}\text { Sense } \\
\text { Antisense }\end{array}$ & $\begin{array}{l}\text { 5'gTTTTTgTTTTTTgTgTggTTgTT3' } \\
\text { 5'CAAAAAACCAACACCTCCСАCC3' }\end{array}$ & 155 & 60 \\
\hline HIC-1M & $\begin{array}{l}\text { Sense } \\
\text { Antisense }\end{array}$ & $\begin{array}{l}\text { 5'TTCgTTTTTCgCgCggTC3' } \\
\text { 5'gAAAAACCAACgCCTCCC3' }\end{array}$ & 151 & 55 \\
\hline
\end{tabular}

Table III. DNMT mRNA levels in HCCs and non-cancerous liver tissues.

\begin{tabular}{lccrr}
\hline & \multicolumn{4}{c}{ DNMT mRNA levels (mean \pm SD) } \\
\cline { 2 - 5 } & Normal $(\mathrm{n}=7)$ & Chronic hepatitis $(\mathrm{n}=11)$ & Cirrhosis $(\mathrm{n}=13)$ & HCC $(\mathrm{n}=25)$ \\
\hline DNMT1 & $3.2 \pm 0.97$ & $3.97 \pm 1.83$ & $3.95 \pm 1.50$ & $13.9 \pm 10.50$ \\
DNMT3a & $13.3 \pm 3.76$ & $22.56 \pm 12.60$ & $24.91 \pm 16.21$ & $59.83 \pm 38.95$ \\
DNMT3b & $1.8 \pm 1.31$ & $2.12 \pm 1.68$ & $1.84 \pm 0.78$ & $9.13 \pm 10.68$ \\
\hline
\end{tabular}

DNMT3b, and from 0.008-5 ng for the 18S rRNA, which corresponded to the amount of the total RNA. The data obtained for the $18 \mathrm{~S}$ rRNA was used to normalize the sample-to-sample variations for the amount of input cDNA and to evaluate the quality of the isolated RNA and RT efficiency, and the primers and probe for the 18S rRNA were purchased from ABI (Applied Biosystems). The PCR reaction for individual samples was carried out with $1 \mu \mathrm{l}$ of the RT reactions, which corresponded to $50 \mathrm{ng}$ of the total RNA, in $25 \mu 1$ containing $1 \mathrm{X}$ TaqMan universal master mix (Applied Biosystems) and 1X Assays-on-Demand ${ }^{\mathrm{TM}}$ gene expression assay mix. The $18 \mathrm{~S}$ rRNA reaction was performed in $25 \mu 1$ with $50 \mathrm{nM}$ of the primers, $200 \mathrm{nM}$ of the probe and cDNA, corresponding to $0.5 \mathrm{ng}$ of the total RNA. The thermal cycling was initiated with 2 min of incubation at $50^{\circ} \mathrm{C}$ to allow the uracil $\mathrm{N}$-glycosylase reaction, followed by $10 \mathrm{~min}$ at $95^{\circ} \mathrm{C}$ to activate the AmpliTaq gold, and $40 \mathrm{PCR}$ cycles at $95^{\circ} \mathrm{C}$ for $15 \mathrm{sec}$ and at $60^{\circ} \mathrm{C}$ for $1 \mathrm{~min}$. All measurements included the determination of the five standards and the 'no template' as a negative control, in which water was substituted for the cDNA. Each sample was analyzed in duplicate or triplicate, and the mean values of the $\mathrm{C}_{t}$ multiplicate were used for the calculations.

Immunohistochemistry. Formalin-fixed, paraffin-embedded tissues were cut into $4-\mu \mathrm{m}$-thick sections and mounted on poly-L-lysine-coated glass slides. Slides were deparaffinized in xylene, rehydrated in graded alcohol and washed in tap water. Endogenous peroxidase activity was blocked by incubating sections in $3 \% \mathrm{H}_{2} \mathrm{O}_{2}$. Slides were placed in a pressure cooker with $10 \mathrm{mM}$ sodium citrate buffer, $\mathrm{pH} 6.0$, for antigen retrieval. Mouse monoclonal antibodies for DNMT1 (IMG-261, 60B1220, dilution 1:125) and DNMT3a (IMG-268, 64B1446, dilution 1:125) (both from Imgenex, 
San Diego, CA) were applied for $1 \mathrm{~h}$. After reaction with a biotinylated anti-mouse antibody for $1 \mathrm{~h}$, antigen-antibody complexes were visualized using a streptavidin-horseradish peroxidase conjugate (LSAB kit; Dako, Carpinteria, CA) with diaminobenzidine as a chromogen. Slides were counterstained with Harris' hematoxylin for 3-5 min. Nuclear positivity for the two proteins was evaluated using the scoring system by Choi et al according to the staining intensity ( 0 , negative; 1 , mild; 2 , moderate; and 3 , severe) and proportion of positive cells $(0$, negative; 1 , positive in $\leq 10 \% ; 2$, positive in $>10 \%$ and $\leq 33 \% ; 3$, positive in $>33 \%$ and $\leq 66 \%$; positive in $>66 \%$ of cells) (19). The two scores were added in each case, and the expression was graded as $-(0), 1+(1$ or 2$)$, $2+(3-5)$ and $3+(6$ or 7$)$.

DNA extraction and methylation-specific PCR (MSP). Tissues were digested in lysis buffer (10 mM Tris, $\mathrm{pH} 8.5$, $10 \mathrm{mM}$ EDTA, $0.5 \% \mathrm{SDS}$ and $100 \mathrm{mM} \mathrm{NaCl}$ ) with proteinase K (20 mg/ml, Gibco BRL). Genomic DNA was extracted with phenolchloroform and precipitated with ethanol. Extracted DNA was modified by sodium bisulfite to determine the methylation status of genes by MSP as previously described (23). PCR for the $p 16$ gene was performed at $94^{\circ} \mathrm{C}$ for $5 \mathrm{~min}$, followed by 28 cycles at $94^{\circ} \mathrm{C}$ for $1 \mathrm{~min}, 65^{\circ} \mathrm{C}$ for $30 \mathrm{sec}$ and $72^{\circ} \mathrm{C}$ for $1 \mathrm{~min}$; the other targets were amplified by 35 cycles. All were finished with an extension for $10 \mathrm{~min}$ at $72^{\circ} \mathrm{C}$. Annealing temperatures of other targets are shown in Table II. The $25-\mu 1$ reaction mixture contained $50 \mathrm{ng}$ of modified DNA, 10 pmol of primers, $0.2 \mathrm{mM}$ dNTPs, and 1 unit of Taq polymerase (Takara, Kyoto, Japan) in 1X PCR buffer (10 $\mathrm{mM} \mathrm{MgCl}$ ). Three independent MSPs were performed for an individual test gene to determine the DNA methylation status of each sample. Sequences of PCR primers are shown in Table II. The PCR products were analyzed on $2.5 \%$ agarose gels, stained with ethidium bromide, and then visualized by UV illumination.

Statistical analysis. Statistical analysis was performed using the SPSS 12.0 software. Differences in mRNA levels between groups were analyzed using the Mann-Whitney U test. Spearman's rank correlation was used to study relationships between continuous variables, including DNMT mRNA levels, DNMT protein expression and various clinicopathological parameters. Disease-free and overall survival rates were determined by the Kaplan-Meier method, and the significance of differences between survival rates was studied using the Log-rank test. Differences or correlations with p-values $<0.05$ were considered significant.

\section{Results}

DNMT mRNA and protein expression in HCC and nonneoplastic livers. The results of the real-time PCR for the three types of DNMT mRNA are shown in Table I, Table III and in Fig. 1. The differences in mRNA expression levels for DNMT1 were statistically significant between HCC and normal livers $(\mathrm{p}<0.001)$, HCC and chronic hepatitis $(\mathrm{p}<0.001)$ and HCC and cirrhosis $(\mathrm{p}<0.001)$. Similar findings were demonstrated for DNMT3a mRNA levels $(p<0.001$ for all three groups) and for DNMT3b mRNA levels $(\mathrm{p}<0.001$
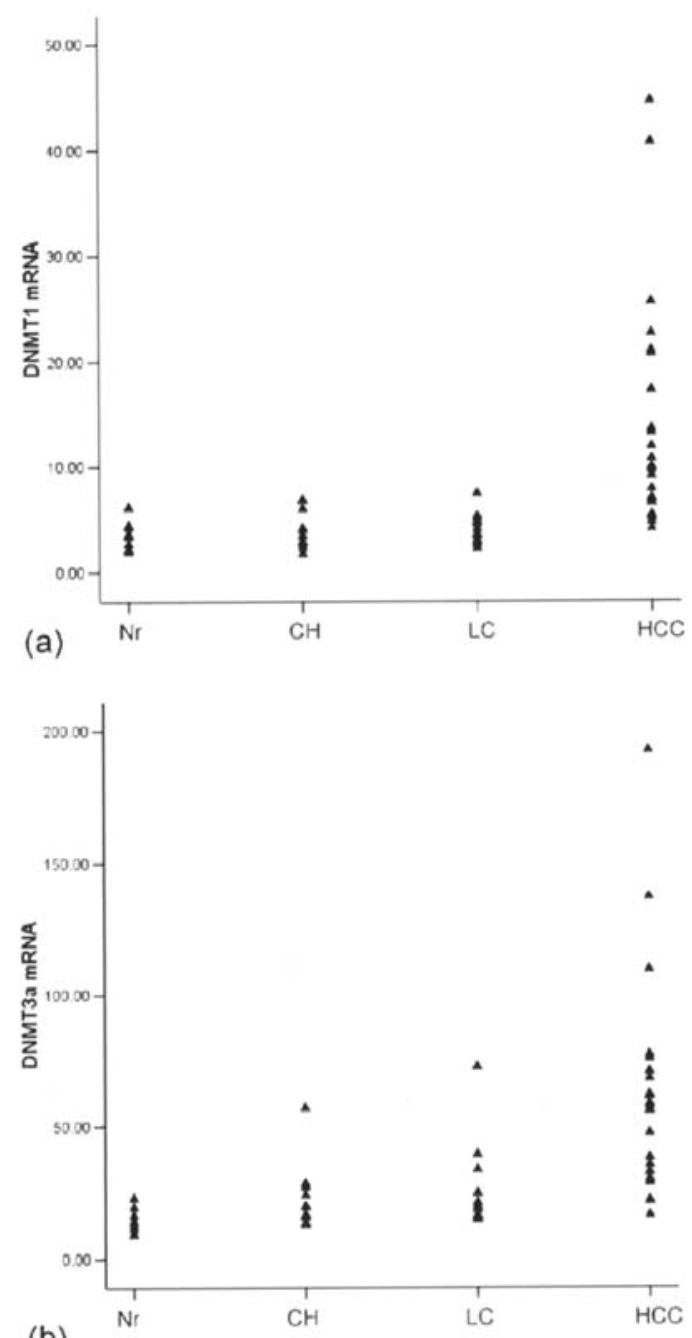

(b)

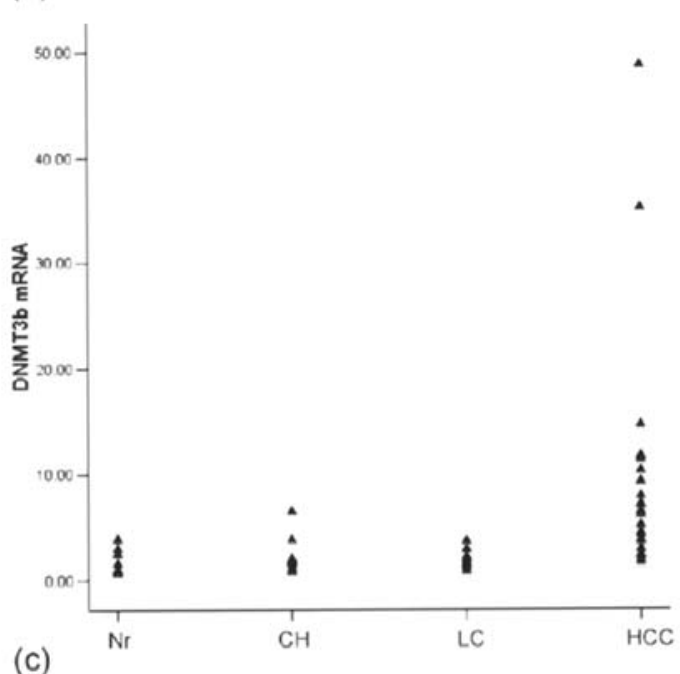

Figure 1. mRNA expression levels of (a) DNMT1, (b) DNMT3a and (c) DNMT3b in normal livers, chronic hepatitis, cirrhosis and hepatocellular carcinomas. $\mathrm{Nr}$, normal; $\mathrm{CH}$, chronic hepatitis; LC, cirrhosis; and $\mathrm{HCC}$, hepatocellular carcinoma.

for all three groups). In addition, the DNMT3a mRNA expression levels in normal livers significantly differed from that of chronic hepatitis, cirrhosis and HCC $(p=0.020$, $\mathrm{p}=0.008$ and $\mathrm{p}<0.001$, respectively). Significant positive 


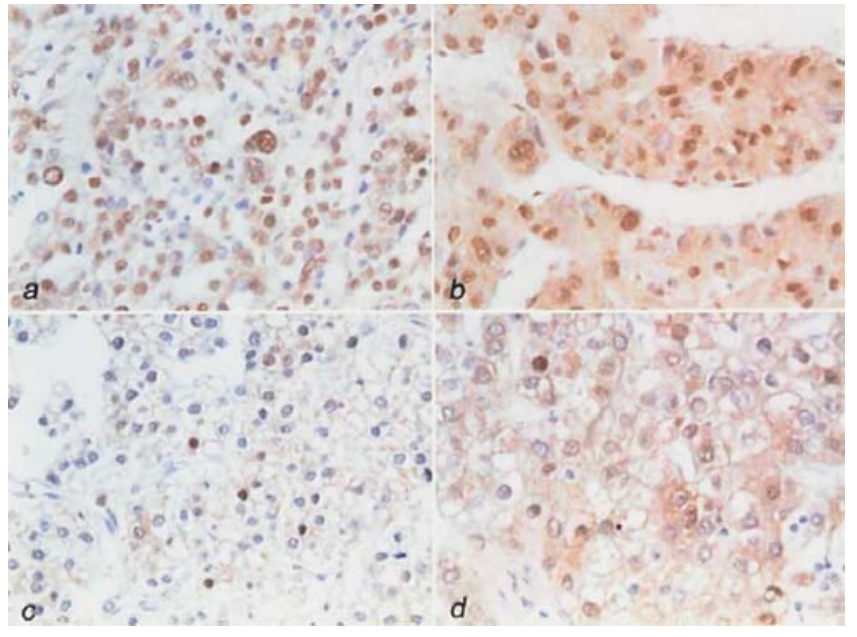

Figure 2. Immunohistochemical stain results for (a,b) DNMT1 and (c,d) DNMT3a proteins in hepatocellular carcinomas. Strong nuclear expression and faint cytoplasmic expression are seen in these four cases.

correlations were found between mRNA levels of DNMT1 and DNMT3b $(\mathrm{p}=0.015)$, and between DNMT3a and DNMT3b $(p=0.001)$ for HCCs. The correlation between mRNA levels of DNMT1 and DNMT3a was weak and not statistically significant $(\mathrm{p}=0.223)$.

There were no significant correlations between DNMT mRNA expression status and age, sex, tumor size, satellite nodule formation, vascular invasion and Edmondson-Steiner grade. Serum $\alpha$-fetoprotein levels were found to be positively correlated with the mRNA levels of DNMT3a $(\mathrm{p}<0.001)$ and DNMT3b ( $\mathrm{p}=0.004)$.

The immunohistochemical stain results are shown in Table I and Fig. 2. All 25 cases of HCC showed at least mild (1+) nuclear expression of DNMT1 protein and the expression was strong $(3+)$ in $4(16 \%)$ cases, while none $(0 \%)$ of the seven normal control livers demonstrated nuclear expression of DNMT1. Seventeen (68\%) of the $25 \mathrm{HCC}$ cases were positive $(1+$ or $2+$ ) for nuclear DNMT3a expression by immunohistochemistry; the expression pattern of DNMT3a in the normal livers was diffuse cytoplasmic expression, with none $(0 \%)$ of the seven cases showing nuclear expression. No statistically significant correlations were noted between the mRNA expression levels and nuclear immunohistochemical expression of DNMT1 or DNMT3a; however, there was a tendency for stronger DNMT3a protein expression in HCCs with higher mRNA expression levels $(\mathrm{p}=0.060)$.

DNA methylation status of p16, p15, E-cadherin, HIC-1 and RASSF1A in HCC and non-neoplastic livers. The results of the MSP are shown in Table IV. The average numbers of methylated genes were $0,1.27,1.38$ and 2.72 for normal livers, chronic hepatitis, cirrhosis and HCCs, respectively. Of the $25 \mathrm{HCCs}, 24(96 \%)$ showed methylation of at least one gene, $22(88 \%)$ demonstrated methylation in more than one gene, and methylation of 4 genes was noted in 7 (28\%) genes. Methylation in at least one gene was noted in $2(28.6 \%)$ normal livers, 7 (63.6\%) chronic hepatitis and 10 (76.9\%) cirrhotic livers, and none $(0 \%)$ of the 24 chronic hepatitis/ cirrhosis cases demonstrated methylation of more than 3 genes. The most frequently methylated genes were RASSF $1 A$ (92\%), E-cadherin (84\%) and HIC-1 (44\%) for HCCs. These three genes were also methylated in chronic hepatitis/ cirrhosis, the frequency ranging from 36.4-53.8\%. However, p16 and p15 methylation was not demonstrated in chronic hepatitis/cirrhosis, in contrast to HCCs with expression of the two genes at 36 and $12 \%$, respectively.

No significant correlation was noted between mRNA expression levels and protein immunoreactivity for the three DNMTs and DNA methylation status for the 5 tested genes.

The effect of DNMT mRNA expression status and DNA methylation status of p16, p15, E-cadherin, HIC-1 and RASSF1A on patient survival. Follow-up information was available for 24 patients, and the patients were tracked for a mean of 44.9 months (range, 4-71 months). Local recurrence was found in 17 patients $(70.8 \%)$, from 2 to 47 months (mean, 17 months) after surgical resection. Five patients (20.8\%) developed distant metastasis from 0 to 18 months (mean, 6.4 months) after surgical resection. Eight patients $(33.3 \%)$ died from 4 to 22 months (mean, 14 months) after primary surgical resection.

Kaplan-Meier survival curves were plotted for our HCC patients according to the fold increase in DNMT mRNA expression (Fig. 3). An increase in mRNA expression levels $>4$-fold for DNMT3b in HCCs was significantly associated with a poorer overall survival $(\mathrm{p}=0.0247)$ and shorter metastasis-free survival $(\mathrm{p}=0.0299)$. A poorer recurrence-free survival was noted in HCCs with $>4$-fold increase in DNMT3a mRNA ( $=0.0120)$. DNMT1 mRNA levels failed to show any associations with patient survival. There was no

Table IV. DNA methylation status on CpG islands in HCCs and non-cancerous liver tissues.

\begin{tabular}{lccrr}
\hline & \multicolumn{4}{c}{ Number of methylated genes $(\%)$} \\
\cline { 2 - 5 } & Normal $(\mathrm{n}=7)$ & Chronic hepatitis $(\mathrm{n}=11)$ & Cirrhosis $(\mathrm{n}=13)$ & HCC $(\mathrm{n}=25)$ \\
\hline p16 & $0(0)$ & $0(0)$ & $0(0)$ & $9(36)$ \\
p15 & $1(14.3)$ & $0(0)$ & $0(0)$ & $3(12)$ \\
E-cadherin & $1(14.3)$ & $5(45.5)$ & $6(46.2)$ & $21(84)$ \\
RASSF1A & $2(28.6)$ & $4(36.4)$ & $5(38.5)$ & $23(92)$ \\
HIC-1 & $1(14.3)$ & $5(45.5)$ & $7(53.8)$ & $11(44)$ \\
\hline
\end{tabular}




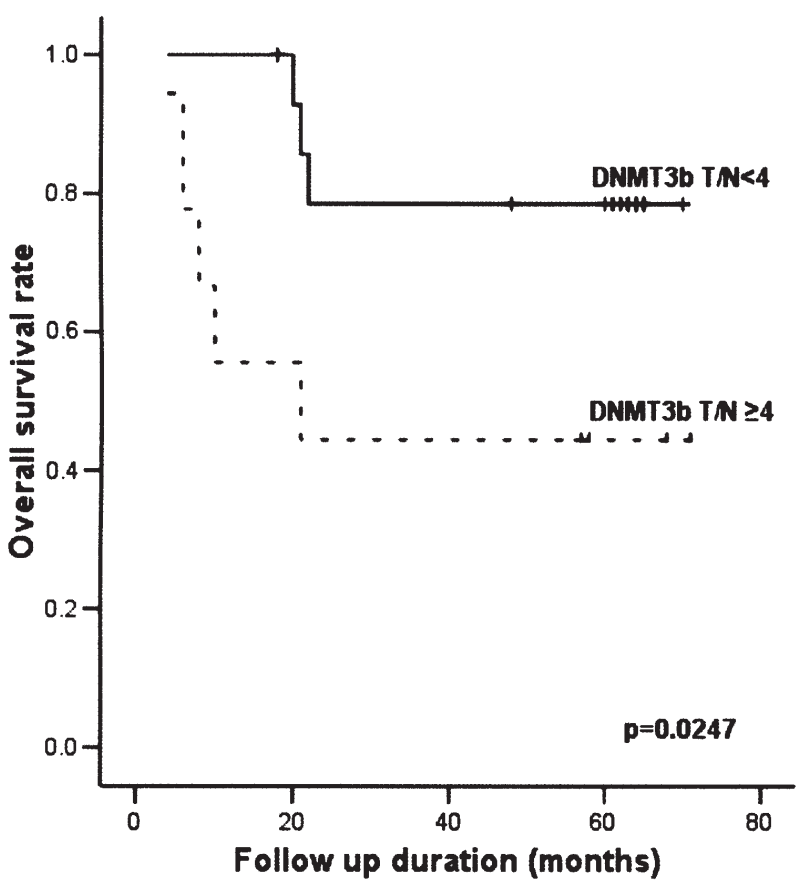

Figure 3. Kaplan-Meier survival curve for patients with hepatocellular carcinoma according to their DNMT3b mRNA expression levels. T/N, tumor/non-tumor mRNA ratio.

significant relationship between patient survival and the three DNMT mRNA levels when analyzed regardless of the mRNA levels in their non-neoplastic tissues. No significant relationships were found between patient prognosis and the DNA methylation status of $p 16, p 15$, E-cadherin, HIC-1 or RASSF $1 A$ in HCC.

\section{Discussion}

Recently it has been suggested that aberrant DNA methylation on $\mathrm{CpG}$ islands is an early and major event during hepatocarcinogenesis, with the number of methylating events increasing along with progression from chronic hepatitis through cirrhosis to dysplastic nodules and $\operatorname{HCC}(4,5,7)$. Higher levels of DNMT mRNA or protein observed in HCCs compared to non-neoplastic livers suggest that the enzyme may be at least partly responsible for the epigenetic events in malignant transformation, however, a clear relationship between DNMT expression and promoter gene methylation has not yet been established.

In this study, we have demonstrated a significant increase in the mRNA levels of DNMT1, DNMT3a and DNMT3b in HCCs compared to non-neoplastic livers, including normal, hepatitic and cirrhotic livers $(\mathrm{p}<0.001)$, and that there were significant positive correlations between the DNMT mRNA levels (DNMT1 vs DNMT3b and DNMT3a vs DNMT3b) in HCCs. The latter finding is in line with that of Girault et al, who observed that DNMT1, DNMT3a and DNMT3b mRNA expression levels correlated positively with each other in their study of 130 breast cancers and suggested that a common regulatory pathway may exist for these three enzymes (24). In addition, the mRNA levels of DNMT3a differed significantly between normal livers and chronic hepatitis $(\mathrm{p}=0.020)$ and between normal and cirrhotic livers $(\mathrm{p}=0.008)$, similar to a previous study that demonstrated significantly higher DNMT3a mRNA levels in chronic hepatitis or cirrhosis than in histologically normal liver tissues (6). However, no significant differences were noted between normal, hepatitic and cirrhotic livers for DNMT1 and DNMT3b mRNA levels in our study.

Our study is the first to search for a relationship between the mRNA expression levels of all three DNMTs and patient survival, and our follow-up data revealed a poorer overall survival and shorter metastasis-free survival in HCC patients with a 4-fold increase in DNMT3b mRNA levels relative to non-neoplastic liver. In addition, a poorer recurrence-free survival was noted in $\mathrm{HCCs}$ with a $>4$-fold increase in DNMT3a mRNA. However, no significant relationships between DNMT1 mRNA expression and patient outcome, including recurrence, metastasis and overall survival, were noted. In addition, significant correlations between serum $\alpha$ fetoprotein levels and mRNA levels of DNMT3a and DNMT3b were noted in this study and together with our data on patient outcome, it could be suggested that DNMT3a and DNMT3b mRNA levels are related more closely to the clinical features of HCCs than DNMT1 mRNA levels.

The relationship between DNMT mRNA expression levels and patient prognosis may justify a role for DNMT inhibitor therapy in HCC patients with increased DNMT mRNA levels. Promoter methylation by DNMT has been shown to be potentially reversible with the DNMT inhibitor 5-aza-2'-deoxycytidine shown to induce re-expression of promoter-methylated genes in cell lines in vitro (25-27). Thus, the DNMT mRNA expression status of HCCs may have important therapeutic implications.

A progressive increase in the number of methylated genes from normal liver to HCC was noted in our methylationspecific PCR study of five tumor suppressor genes; $p 16, p 15$, E-cadherin, HIC-1 and RASSF $1 A$. The average numbers of methylated genes were $0,1.27,1.38$ and 2.72 for normal livers, chronic hepatitis, cirrhosis and HCCs, respectively. The frequency of methylation of at least one gene was 28.6, $63.6,76.9$, and $96 \%$ in normal livers, chronic hepatitis, cirrhosis and HCCs, respectively. However, a high level of epigenetic alteration with methylation in more than 3 genes was not observed in any of the chronic hepatitis/cirrhosis cases compared to $28 \%$ of HCCs. The fact that there is an increase in the number of methylated genes for chronic hepatitis and cirrhosis compared to normal livers in our study is a notable finding, as it suggests that tumor suppressor gene methylation may be an early event in hepatocarcinogenesis and that chronic liver disease, such as chronic hepatitis and cirrhosis, may serve as a soil for HCC development. In fact, a significant proportion of hepatocytes in chronic hepatitis and cirrhosis have demonstrated senescence and telomere shortening compared to normal liver $(28,29)$. Therefore, disturbances of the cell cycle check-point and DNA repair system might result in the failure to clear or repair damaged hepatocytes.

When comparing the methylation status of the 5 genes (p16, p15, E-cadherin, RASSF1A and HIC-1) between HCCs and chronic hepatitis/cirrhosis, we found that methylation of RASSF1A was found in chronic hepatitis/cirrhosis, although 
it was much more frequent in HCCs $(37.5 \%$ in chronic hepatitis/cirrhosis vs. $92 \%$ in HCCs, respectively). RASSF $1 A$ is a cell cycle-related tumor suppressor protein which inhibits cyclin D1 and subsequently induces G1 phase arrest. Therefore methylation of RASSF1A might permit damaged hepatocytes to proceed further into the cell cycle by escaping G1 phase arrest. Similarly, methylation of E-cadherin was found in the stage of chronic hepatitis/cirrhosis (45.8\%), although it was more frequent in HCCs $(84 \%)$. In contrast, p15 and p16, two cyclin-dependent kinase 4/6 inhibitors, were exclusively methylated in HCCs. The frequency of methylation of $\mathrm{HIC}-1$ was similar between the two groups (44\% in HCCs vs. $41.9 \%$ in non-neoplastic tissues). This result conforms to that of a previous study by Park et al which demonstrated that $H I C-1$ was methylated with similar frequencies in HCCs and non-tumoral liver (85.2 vs. 88.9\%, respectively) (10). The authors suggested that hemimethylation of HIC-1 may explain this finding as the DNA was observed in both unmethylated and methylated states. Moreover, the observation of hemimethylation of HIC-1 in normal breast ductal tissues and normal prostate epithelium supports the possibility of hemimethylation of $\mathrm{HIC}-1$ in nonneoplastic liver tissues $(30,31)$.

There was no significant relationship between the frequency of promoter gene methylation and DNMT mRNA expression levels for the three DNMTs in our HCCs, which is in accord with most in vivo studies of various cancers $(6,18,21,22)$. It has been suggested that although DNMTs may cause gene inactivation through $\mathrm{CpG}$ island hypermethylation, increased DNMT mRNA expression itself may not be sufficient to repress target gene expression and that other mechanisms, such as viral infection, may be involved in gene silencing (10). Another possible explanation would be the presence of splice variants of DNMT mRNA producing isoforms of the DNMT proteins (32-34). In addition, no significant relationships were found between the degree of promoter gene methylation and patient survival or between the methylation status of each individual gene and survival. A more extensive study with a larger patient population and longer follow-up may be necessary to examine such associations.

In conclusion, our study demonstrates that hepatocarcinogenesis involves an increased expression of DNMT1, DNMT3a and DNMT3b mRNA and that there is a progressive increase in the number of methylated genes from normal liver, chronic hepatitis/cirrhosis to HCC. It is also suggested that an increase in the DNMT3a and DNMT3b mRNA levels in HCCs relative to their non-cancerous tissues may be a predictor of poor survival.

\section{Acknowledgements}

This study was supported by FG06-11-04 of the 21C Frontier Functional Human Genome Project from the Ministry of Science and Technology in Korea, by a grant from Seoul Research and Business Development Program (10816), partly by the BioGreen21 Program, Rural Development Administration, Republic of Korea (to Y-H.S.), the second BK21, MOE (to Y-H.S.), and KOSEF through the Cancer Metastasis Research Center at Yonsei University College of Medicine (R11-2000-082-02008-0) (to B.O.).

\section{References}

1. Jones PA and Baylin SB: The fundamental role of epigenetic events in cancer. Nat Rev 3: 415-428, 2002.

2. Nephew KP and Huang TH: Epigenetic gene silencing in cancer initiation and progression. Cancer Lett 190: 125-133, 2003.

3. Garinis GA, Patrinos GP, Spanakis NE and Menounos PG: DNA hypermethylation: when tumour suppressor genes go silent. Hum Genet 111: 115-127, 2002.

4. Roncalli M, Bianchi P, Bruni B, et al: Methylation framework of cell cycle gene inhibitors in cirrhosis and associated hepatocellular carcinoma. Hepatology 36: 427-432, 2002.

5. Lee S, Lee HJ, Kim JH, Lee HS, Jang JJ and Kang GH: Aberrant $\mathrm{CpG}$ island hypermethylation along multistep hepatocarcinogenesis. Am J Pathol 163: 1371-1378, 2003.

6. Saito Y, Kanai Y, Sakamoto M, Saito H, Ishii H and Hirohashi S: Expression of mRNA for DNA methyltransferases and methylCpG-binding proteins and DNA methylation status on CpG islands and pericentromeric satellite regions during human hepatocarcinogenesis. Hepatology 33: 561-568, 2001.

7. Yang B, Guo M, Herman JG and Clark DP: Aberrant promoter methylation profiles of tumor suppressor genes in hepatocellular carcinoma. Am J Pathol 163: 1101-1107, 2003.

8. Ishiguro A, Takahata T, Saito M, et al: Influence of methylated p15INK4b and p16INK4a genes on clinicopathological features in colorectal cancer. J Gastroenterol Hepatol 21: 1334-1339, 2006.

9. Kondo Y, Kanai Y, Sakamoto M, Mizokami M, Ueda R and Hirohashi S: Genetic instability and aberrant DNA methylation in chronic hepatitis and cirrhosis - a comprehensive study of loss of heterozygosity and microsatellite instability of 39 loci and DNA hypermethylation on $8 \mathrm{CpG}$ islands in microdissected specimen from patients with hepatocellular carcinoma. Hepatology 32: 970-979, 2000

10. Park HJ, Yu E and Shim YH: DNA methyltransferase expression and DNA hypermethylation in human hepatocellular carcinoma. Cancer Lett 233: 271-278, 2006.

11. Di Gioia S, Bianchi P, Destro A, et al: Quantitative evaluation of RASSF1A methylation in the non-lesional, regenerative and neoplastic liver. BMC Cancer 6: 89, 2006.

12. Kanai Y, Ushijima S, Hui AM, et al: The E-cadherin gene is silenced by $\mathrm{CpG}$ methylation in human hepatocellular carcinomas. Int J Cancer 71: 355-359, 1997.

13. Kanai Y, Hui AM, Sun L, et al: DNA hypermethylation at the D17S5 locus and reduced HIC-1 mRNA expression are associated with hepatocarcinogenesis. Hepatology 29: 703-709, 1999.

14. Bestor TH: Activation of mammalian DNA methyltransferase by cleavage of a $\mathrm{Zn}$ binding regulatory domain. Eur Mol Biol Org J 11: 2611-2617, 1992

15. Okano M, Xie S and Li E: DNMT2 is not required for de novo and maintenance methylation of viral DNA in embryonic stem cells. Nucleic Acids Res 26: 2536-2540, 1998.

16. Okano M, Bell DW, Haber DA and Li E: DNA methyltransferases DNMT3a and DNMT3b are essential for de novo methylation and mammalian development. Cell 99: 247-257, 1999 .

17. Bird A: DNA methylation patterns and epigenetic memory. Genes Dev 16: 6-21, 2002

18. Nagai M, Nakamura A, Makino R and Mitamura K: Expression of DNA (5-cytosin)-methyltransferases (DNMTs) in hepatocellular carcinomas. Hepatol Res 26: 186-191, 2003.

19. Choi MS, Shim YH, Hwa JY, et al: Expression of DNA methyltransferases in multistep hepatocarcinogenesis. Hum Pathol 34 11-17, 2003.

20. Saito Y, Kanai Y, Nakagawa T, et al: Increased protein expression of DNA methyltransferase (DNMT) 1 is significantly correlated with the malignant potential and poor prognosis of human hepatocellular carcinomas. Int J Cancer 105: 527-532, 2003.

21. Eads CA, Danenberg KD, Kawakami K, Saltz LB, Danenberg PV and Laird PW: $\mathrm{CpG}$ island hypermethylation in human colorectal tumors is not associated with DNA methyltransferase overexpression. Cancer Res 59: 2302-2306, 1999.

22. Oue N, Kuraoka K, Kuniyasu H, et al: DNA methylation status of hMLH1, p16(INK4a), and CDH1 is not associated with mRNA expression levels of DNA methyltransferase and DNA demethylase in gastric carcinomas. Oncol Rep 8: 1085-1089, 2001 . 
23. Herman JG, Graff JR, Myohanen S, Nelkin D and Baylin SB: Methylation-specific PCR: a novel PCR assay for methylation status of CpG islands. Proc Natl Acad Sci USA 93: 9821-9826, 1996.

24. Girault I, Tozlu S, Lidereau R and Bieche I: Expression analysis of DNA methyltransferases 1, 3A and 3B in sporadic breast carcinomas. Clin Cancer Res 9: 4415-4422, 2003.

25. Juttermann R, Li E and Jaenisch R: Toxicity of 5-aza-2'deoxycytidine to mammalian cells is mediated primarily by covalent trapping of DNA methyltransferase rather than DNA demethylation. Proc Natl Acad Sci USA 91: 11797-11801, 1994

26. Yang X, Phillips DL, Ferguson AT, Nelson W, Herman JG and Davidson NE: Synergistic activation of functional estrogen receptor (ER)-alpha by DNA methyltransferase and histone deacetylase inhibition in human ER-alpha-negative breast cancer cells. Cancer Res 61: 7025-7029, 2001.

27. Arai M, Yokosuka O, Hirasawa Y, et al: Sequential gene expression changes in cancer cell lines after treatment with the demethylation agent 5-aza-2'-deoxycytidine. Cancer 106: 2514-2525, 2006.

28. Shay JW and Roninson IB: Hallmarks of senescence in carcinogenesis and cancer therapy. Oncogene 23: 2919-2933, 2004.
29. Wiemann SU, Satyanarayana A, Tsahuridu M, et al: Hepatocyte telomere shortening and senescence are general markers of human liver cirrhosis. FASEB J 16: 935-942, 2002.

30. Fujii H, Biel MA, Zhou W, Weizman SA and Baylin SB: Methylation of the HIC1 candidate tumor suppressor gene in human breast cancer. Oncogene 16: 2159-2164, 1998.

31. Morton RA, Watkins JJ, Bova GS, Wales MM, Baylin SB and Isaacs WB: Hypermethylation of chromosome 17p locus D17S5 in human prostate tissue. J Urol 156: 512-516, 1996.

32. Bonfils C, Beaulieu N, Chan E, Cotton-Montpetit J and MacLeod AR: Characterization of the human DNA methyltransferase splice variant Dnmt1b. J Biol Chem 275: 10754-10760, 2000.

33. Saito Y, Kanai Y, Sakamoto M, Saito H, Ishii H and Hirohashi S: Overexpression of a splice variant of DNA methyltransferase 3b, DNMT3b4, associated with DNA hypomethylation on pericentromeric satellite regions during human hepatocarcinogenesis. Proc Natl Acad Sci USA 99: 10060-10065, 2002.

34. Weisenberger DJ, Velicescu M, Cheng JC, Gonzales FA, Liang G and Jones PA: Role of the DNA methyltransferase variant DNMT3b3 in DNA methylation. Mol Cancer Res 2: 62-72, 2004 